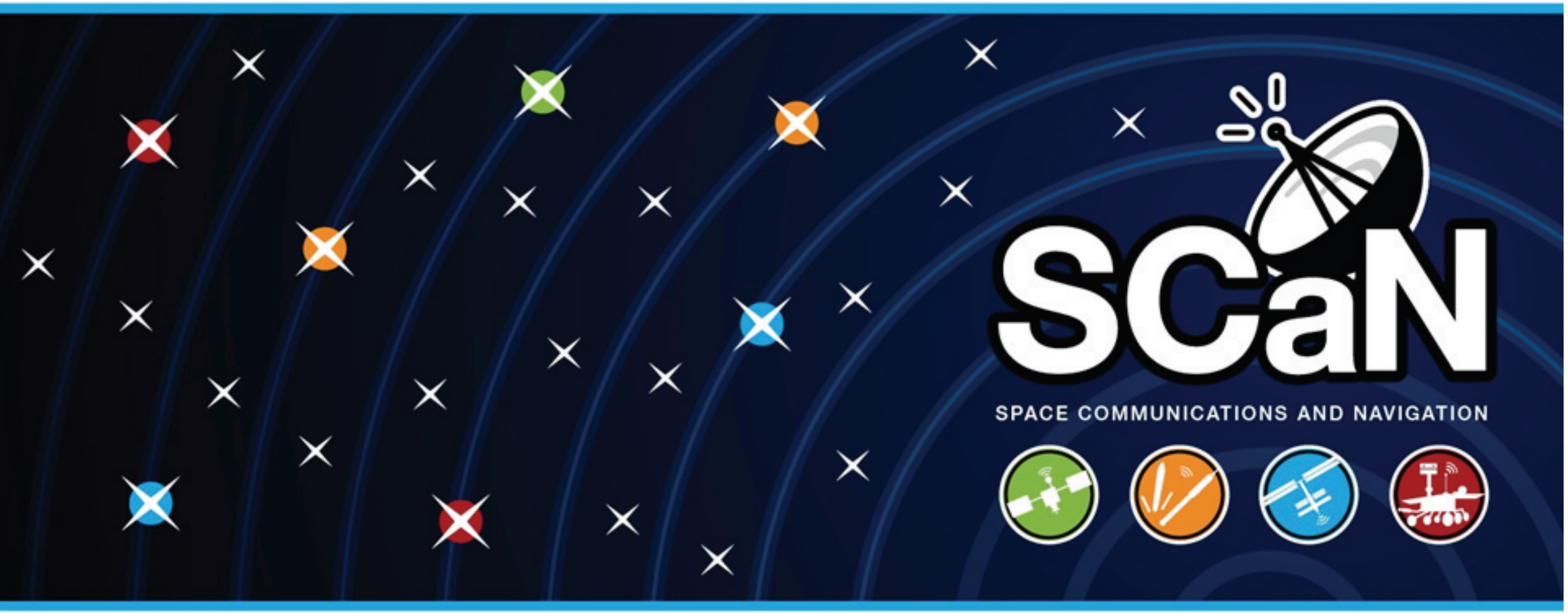

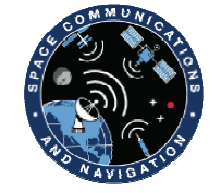

Keeping the universe connected.

www.nasa.gov

\section{Frequency Estimator Performance for a Software-Based Beacon} Receiver

Session 434: Propagation and Scattering in Random or Complex Media

Michael J. Zemba, Jacquelynne R. Morse, and James A. Nessel NASA Glenn Research Center

Cleveland, $\mathrm{OH}$

July $10^{\text {th }}, 2014$

$\bullet$

2014 IEEE AP-S \& USNC-URSI

-

Memphis, TN 


\section{Presentation Overview}

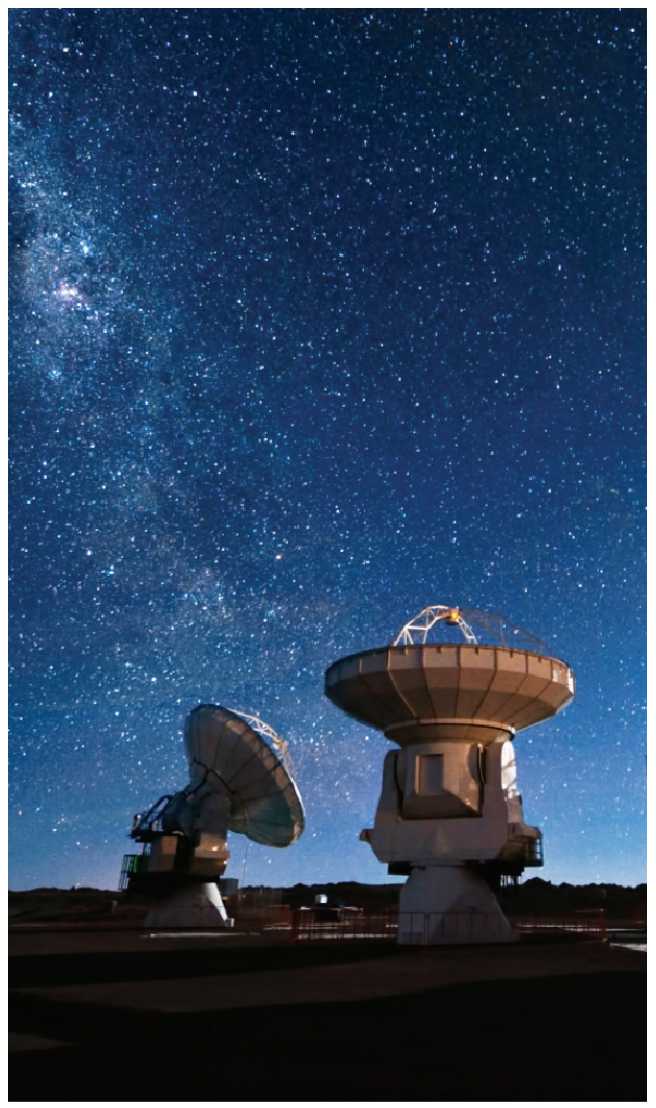

1. Technical Motivation

2. Site of Study

3. Beacon Receiver Hardware

4. Beacon Receiver Software

5. Frequency Estimators

6. Measured Results

- Frequency

- Doppler Shift

7. Conclusions \& Future Work 


\section{Technical Motivation}

Propagation studies at a given site are valuable in designing efficient, cost effective ground stations without sacrificing performance or availability. ${ }^{[1]}$

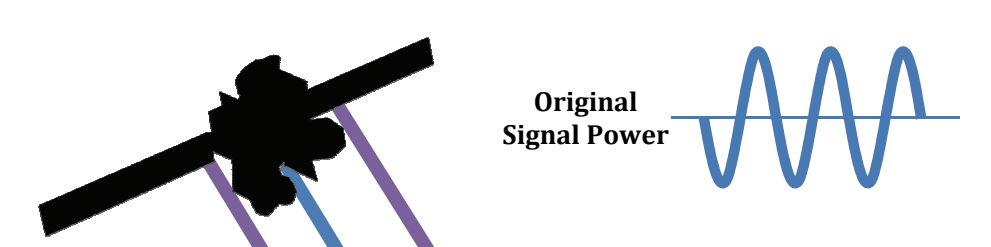

Beacon receiver measurements can be used to characterize the attenuation of a link due to rain, clouds, and gases in the atmosphere. ${ }^{[1]} \mathrm{A}$ beacon onboard a geostationary satellite transmits a CW signal and the power is measured on the ground by the receiver. This measurement will exhibit fluctuations with atmospheric conditions, which are then used to statistically characterize the site's

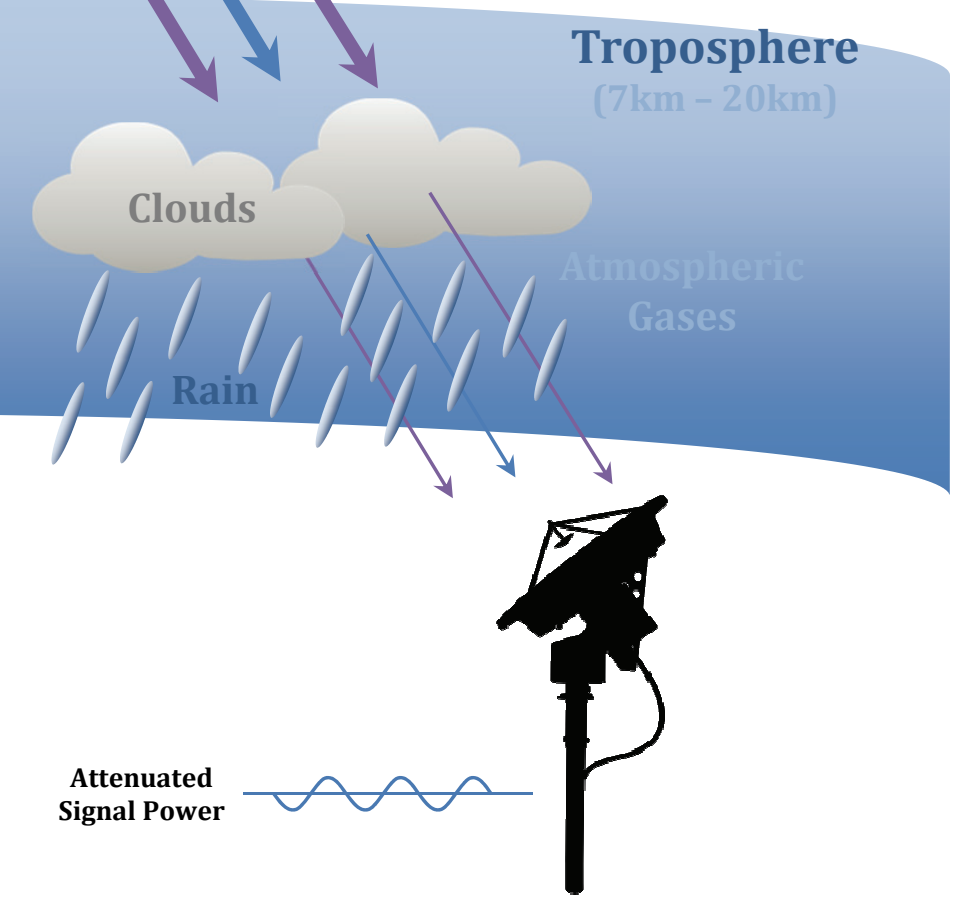
atmospheric attenuation.

Beacon Receiver 


\section{Site of Study}

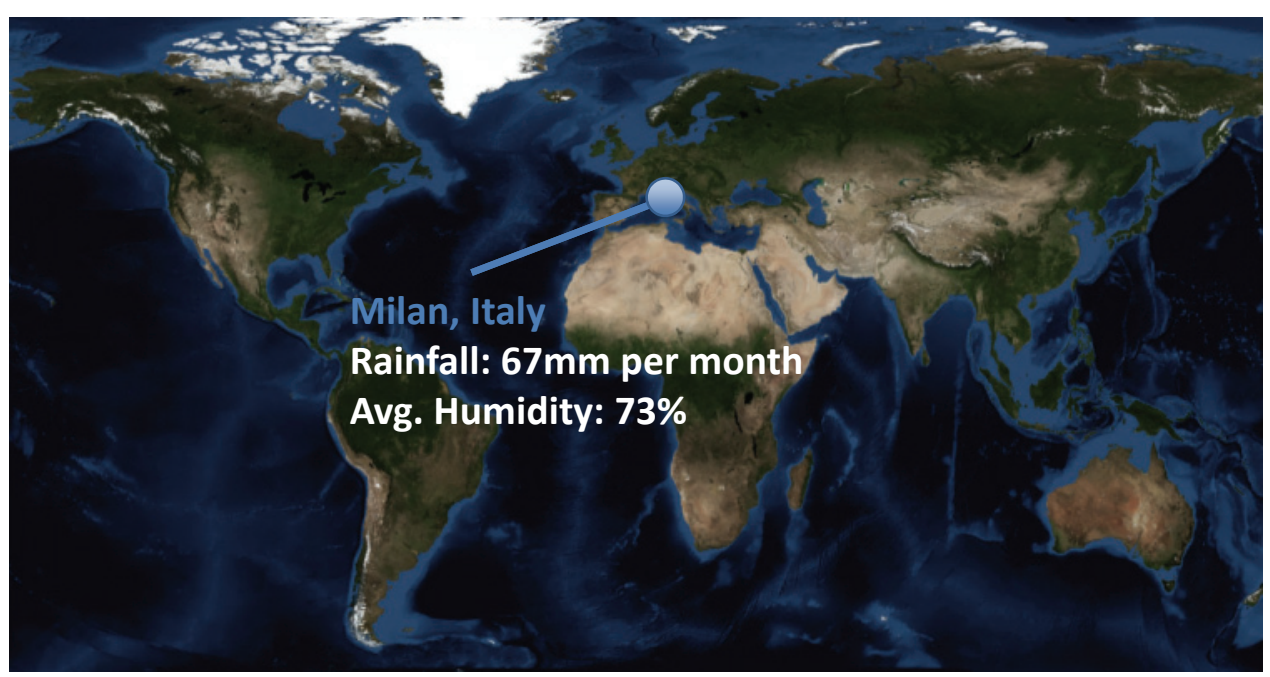

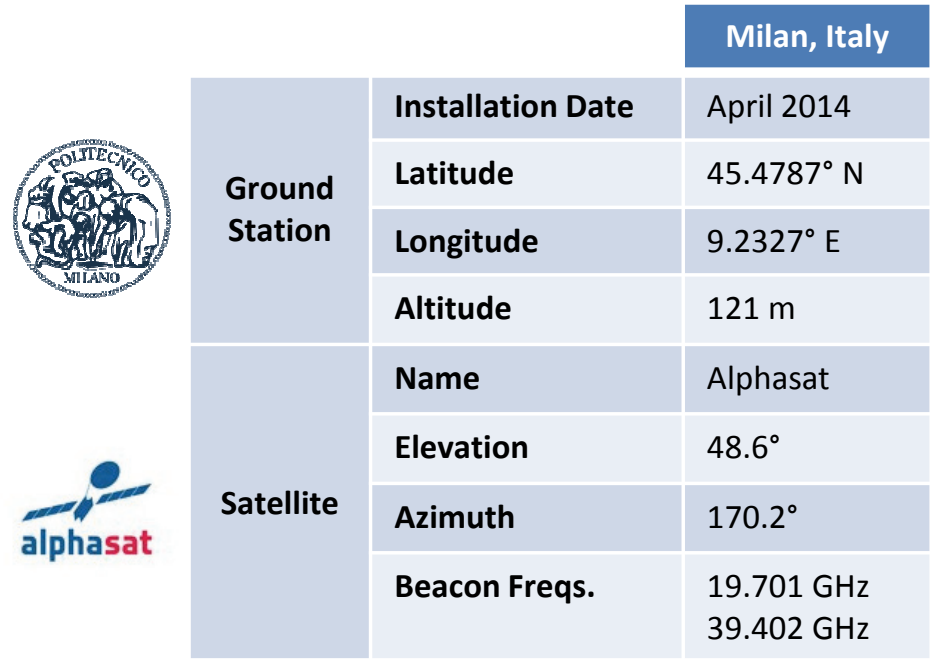

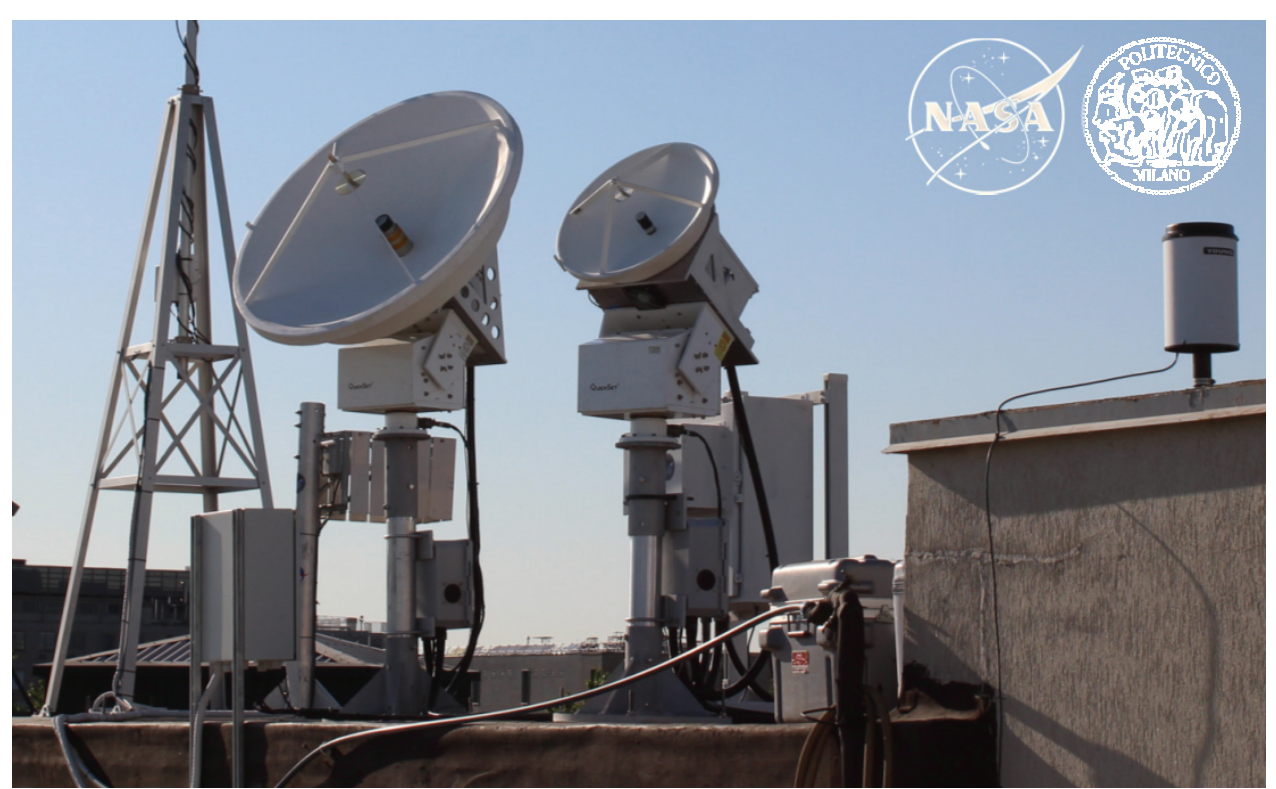

To characterize atmospheric propagation effects at Ka-band $(20 \mathrm{GHz})$ and Q-band (40 GHz), a dual Ka/Q-band beacon receiver was deployed to Milan, Italy in a collaboration between NASA Glenn Research Center and the Politecnico di Milano, utilizing the beacons onboard the Alphasat satellite (launched July 2013). 


\section{Beacon Receiver Hardware}

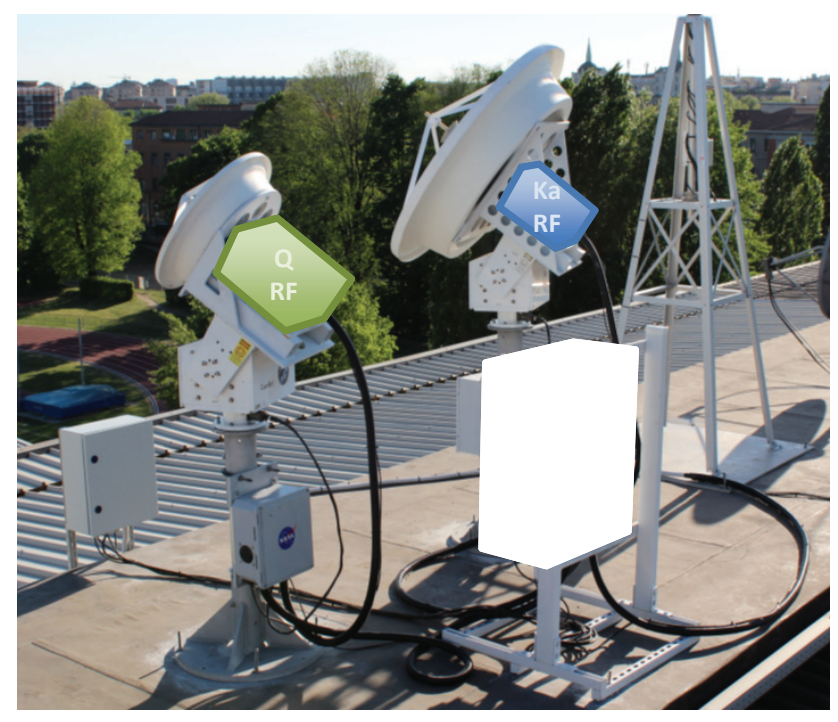

System Specifications

Downconversion (Ka) 3-step down to $455 \mathrm{kHz}$ Downconversion (Q) 4-step down to $455 \mathrm{kHz}$ Sampling Rate $1.111 \mathrm{MHz}$ Number of Points 2 Integration Time $125 \mathrm{~ms}$

Time Series Output Rate $8 \mathrm{~Hz}$ Dynamic Range $40 \mathrm{~dB}$

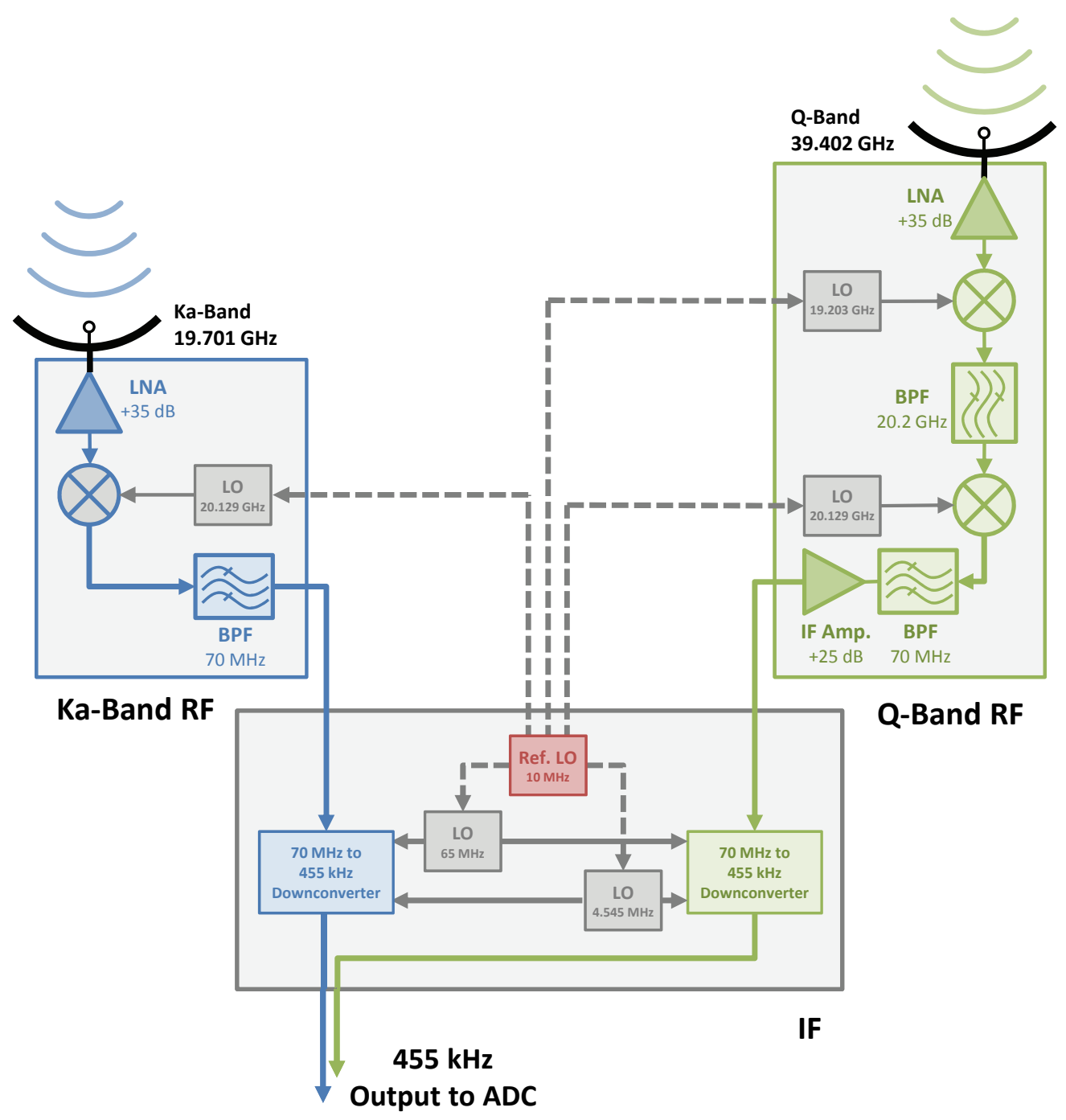




\section{Beacon Receiver Software}

\section{Basic FFT Approach}

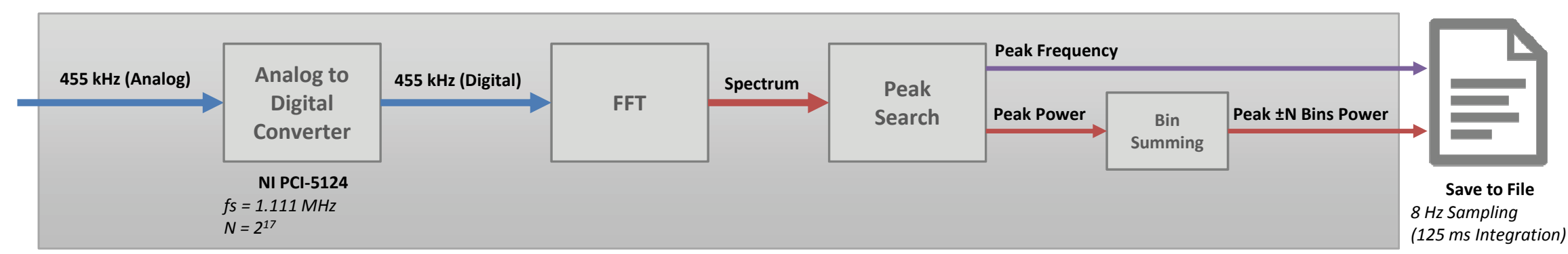

- Frequency Resolution of $\mathrm{fs} / \mathrm{N}$

- Error in Power Measurement (Scalloping)

\section{Frequency Estimator Approach}

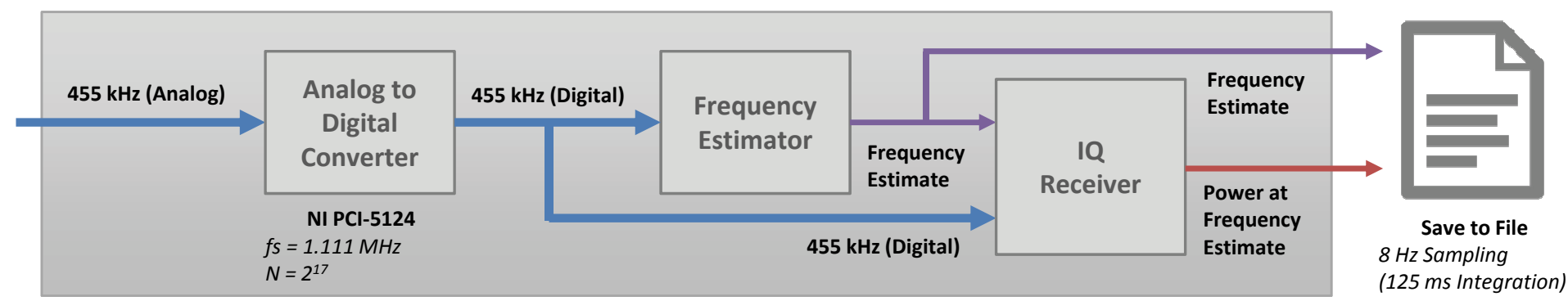

- Increased Frequency Resolution \& Accuracy

- Increased Power Measurement Accuracy (No Scalloping) 


\section{FFT Frequency Estimation}
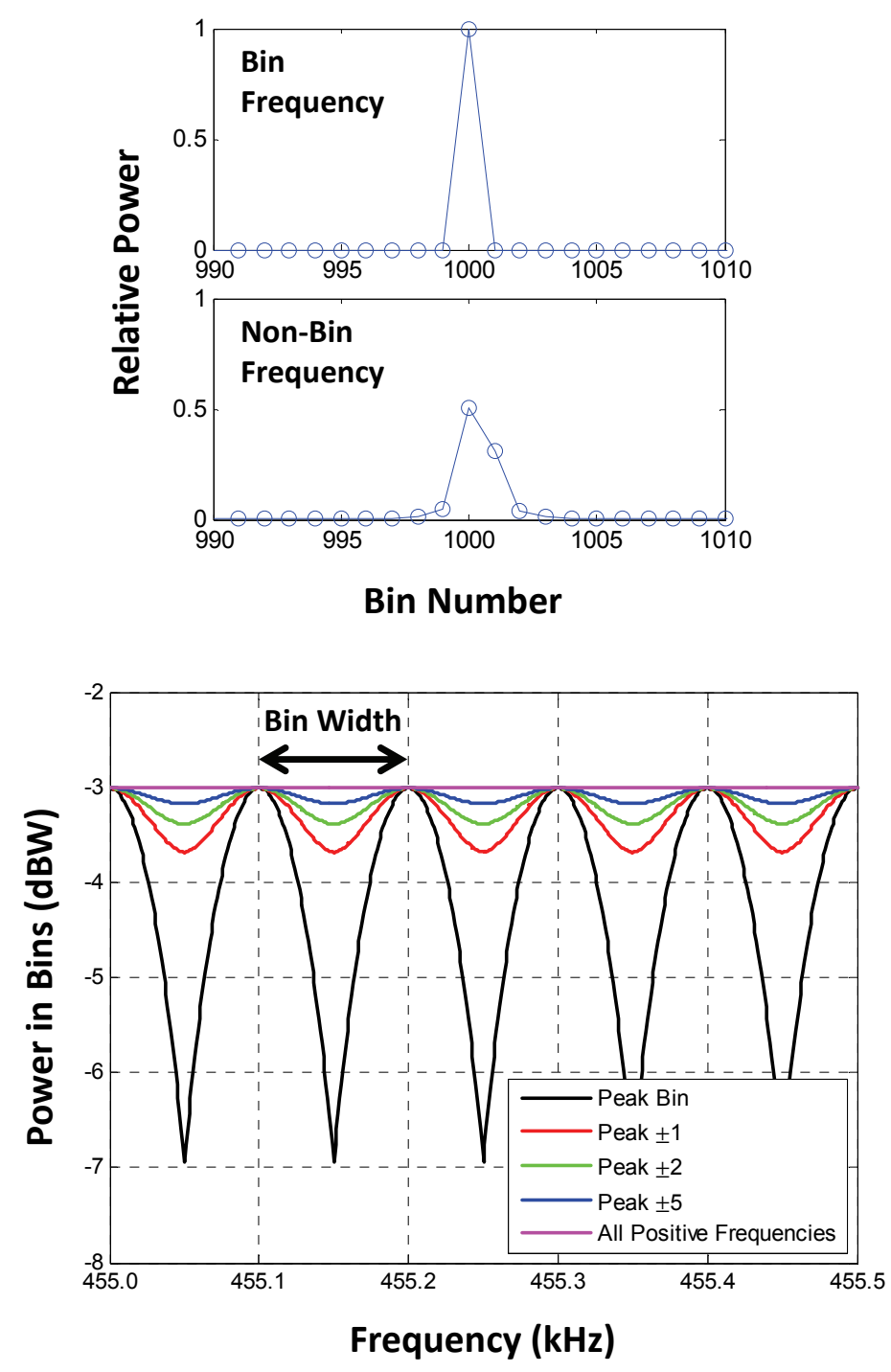

Although FFTs can be used to easily estimate frequency, the resolution is defined by bins of width $\frac{f_{s}}{N}$ (where $\mathrm{f}_{\mathrm{s}}$ is the sampling frequency of the signal and $\mathrm{N}$ is the number of points). This requires careful selection of fs and $\mathrm{N}$ to set the desired resolution.

Additionally, when the frequency of the signal is not exactly a bin frequency, the power of the signal is distributed into neighboring bins. As the frequency of a signal drifts, this creates a scalloping effect in the power measurement.

Alternatively, a variety of algorithms can be used to interpolate the frequency when it is between the bins of the FFT, giving us more freedom to select $\mathrm{f}_{\mathrm{s}}$ and $\mathrm{N}$ based on other criteria, and stabilizing the power measurement. 


\section{FFT vs. Frequency Estimator}
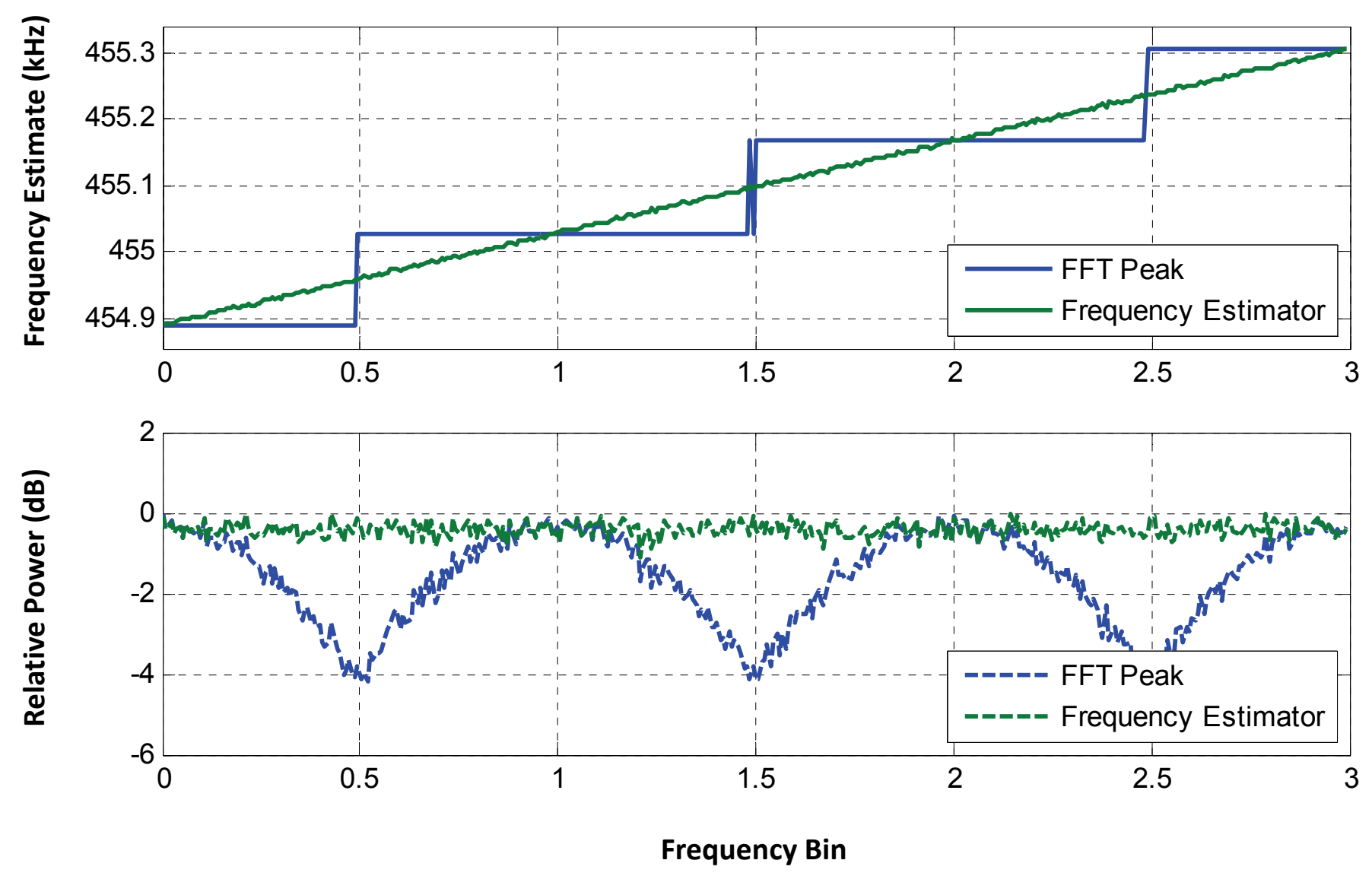


\section{Frequency Estimation Algorithms}

In addition to the FFT, the performance of six frequency estimators was simulated to select one for usage in the Alphasat receiver software:

- $\quad$ FFT Peak - Simply estimates the frequency by locating the peak bin of the Fast Fourier Transform.

- Quinn-Fernandes - Quinn, B.G. and Fernandes, J.M., "A fast technique for the estimation of frequency", Biometrika, 78(3) (1991), pp. 489497. [2]

- Quinn-Fernandes-Nessel - The same implementation as the Quinn-Fernandes method above, but modified to include optional optimization through a priori frequency information.

- Buneman - A frequency estimation algorithm included in LabVIEW, http://digital.ni.com/public.nsf/allkb/4D01B90 DCBAD81C0862570FC005A914E. ${ }^{[3]}$
- Quinn's Method - Quinn, B.G., "Estimating frequency by interpolation using Fourier coefficients," IEEE Trans. Sig. Proc. Vol 42 No 5, May 1994, pp1264-1268.

- Jacobsen - Jacobsen, E.A., "On Local Interpolation of DFT

Outputs," <http://www.ericjacobsen.org/FTinte rp.pdf>, Fall, 1994.

- $\quad$ Macleod-Macleod, M.D., "Fast Nearly ML Estimation of the Parameters of Real or Complex Single Tones or Resolved Multiple Tones," IEEE Trans. Sig. Proc. Vol 46 No 1, January 1998, pp141-148. 


\section{Simulated Frequency Estimate \& Power NASA}

+10dB SNR

$-10 d B$ SNR

$-20 \mathrm{~dB}$ SNR

Frequency Estimate
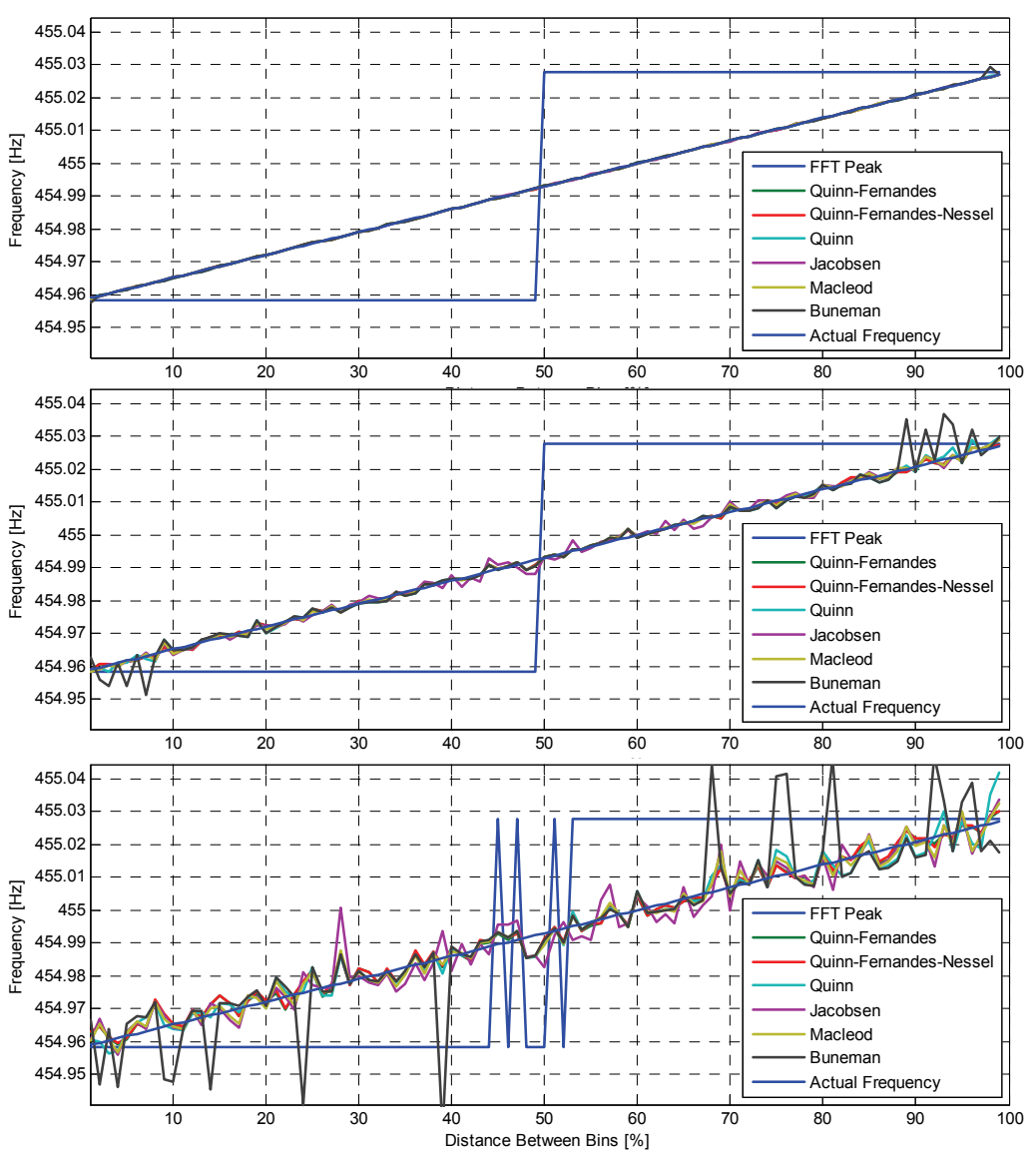

Distance Between Bins
Relative Power
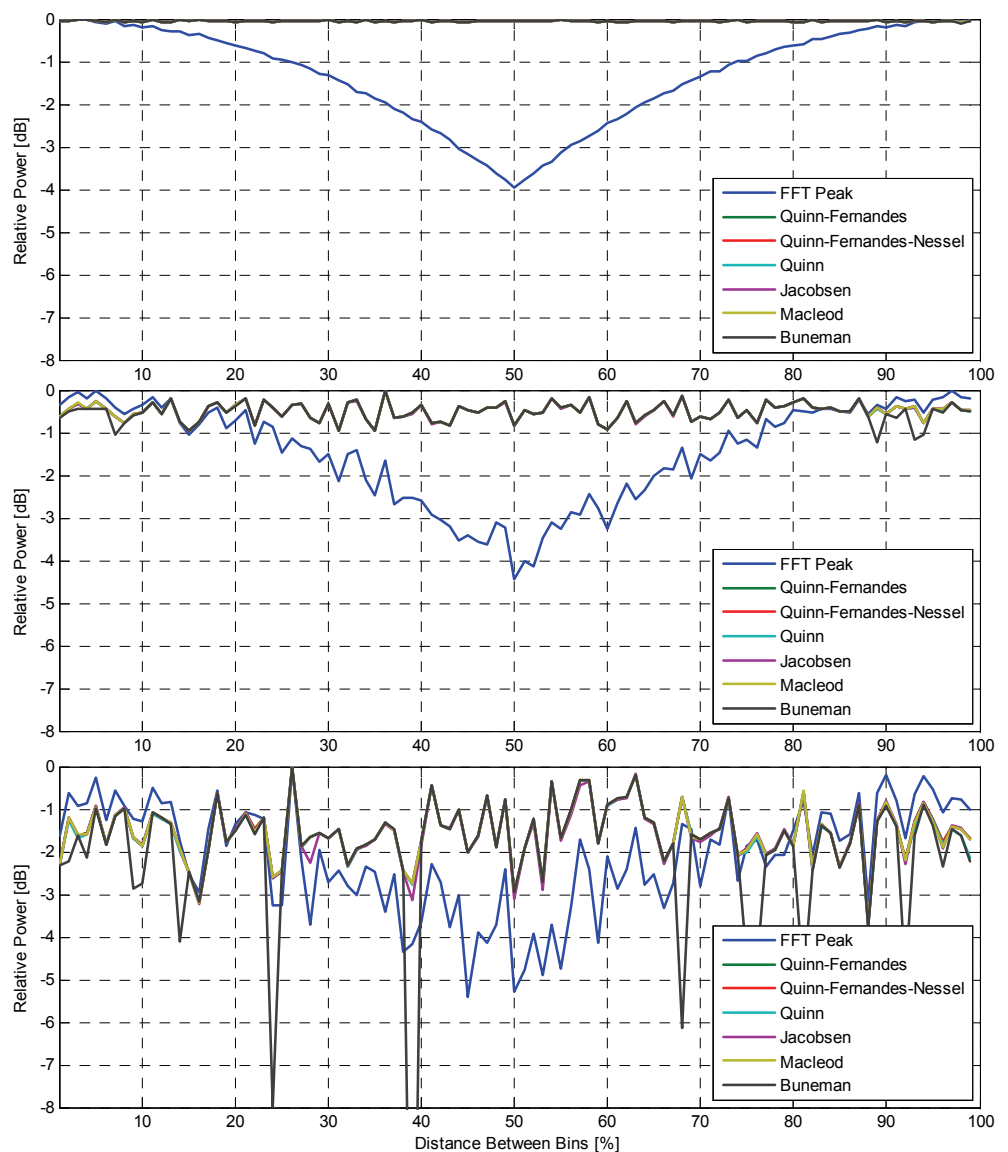

Distance Between Bins 


\section{RMS Error vs. SNR}

RMS (Deviation from Actual Frequency) vs. SNR fs $=4550 ; \mathrm{N}=65536 ; \mathrm{fs} / \mathrm{N}=0.069427$

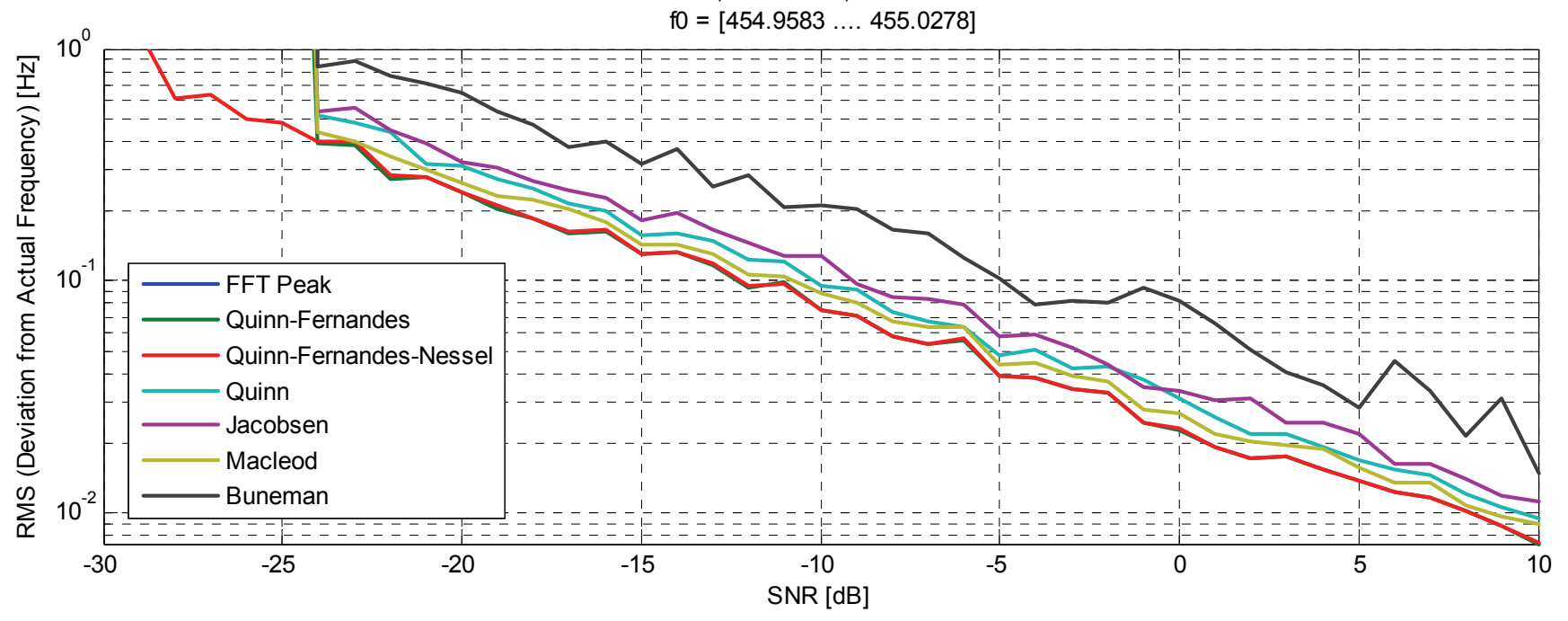

With SNR varying from -30 to $+10 \mathrm{~dB}$, each algorithm's error with respect to the actual frequency (RMS) is plotted on a semi-log scale above.

All six methods (excluding the FFT) exhibited an exponential increase in RMS error as the SNR decreases. At approximately $-24 \mathrm{~dB}$ SNR, the noise at any point in the spectrum may exceed the peak of the FFT, and most of the methods therefore become unable to track the frequency. Quinn-Fernandes-Nessel manages to survive below this point because of the $a$ priori information it is given on where to look for the peak. 


\section{Measured Frequency}
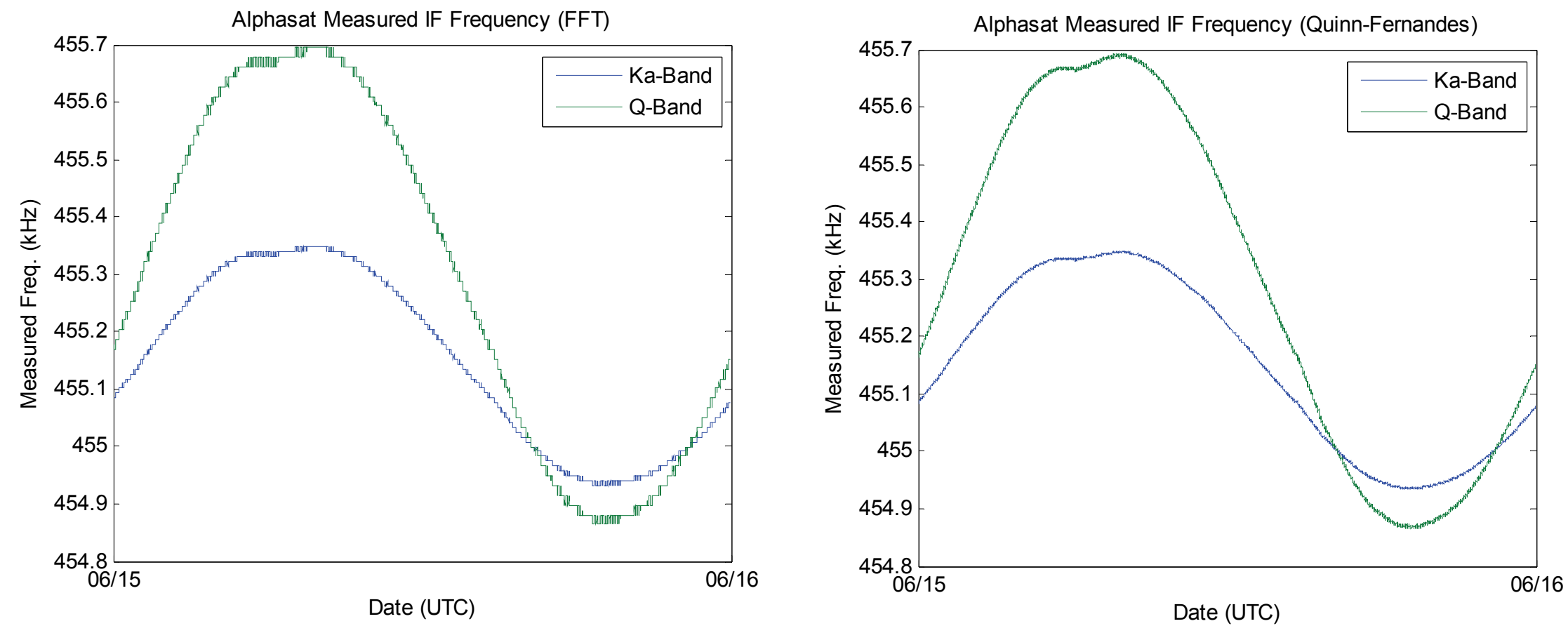


\section{Measured Doppler Shift}

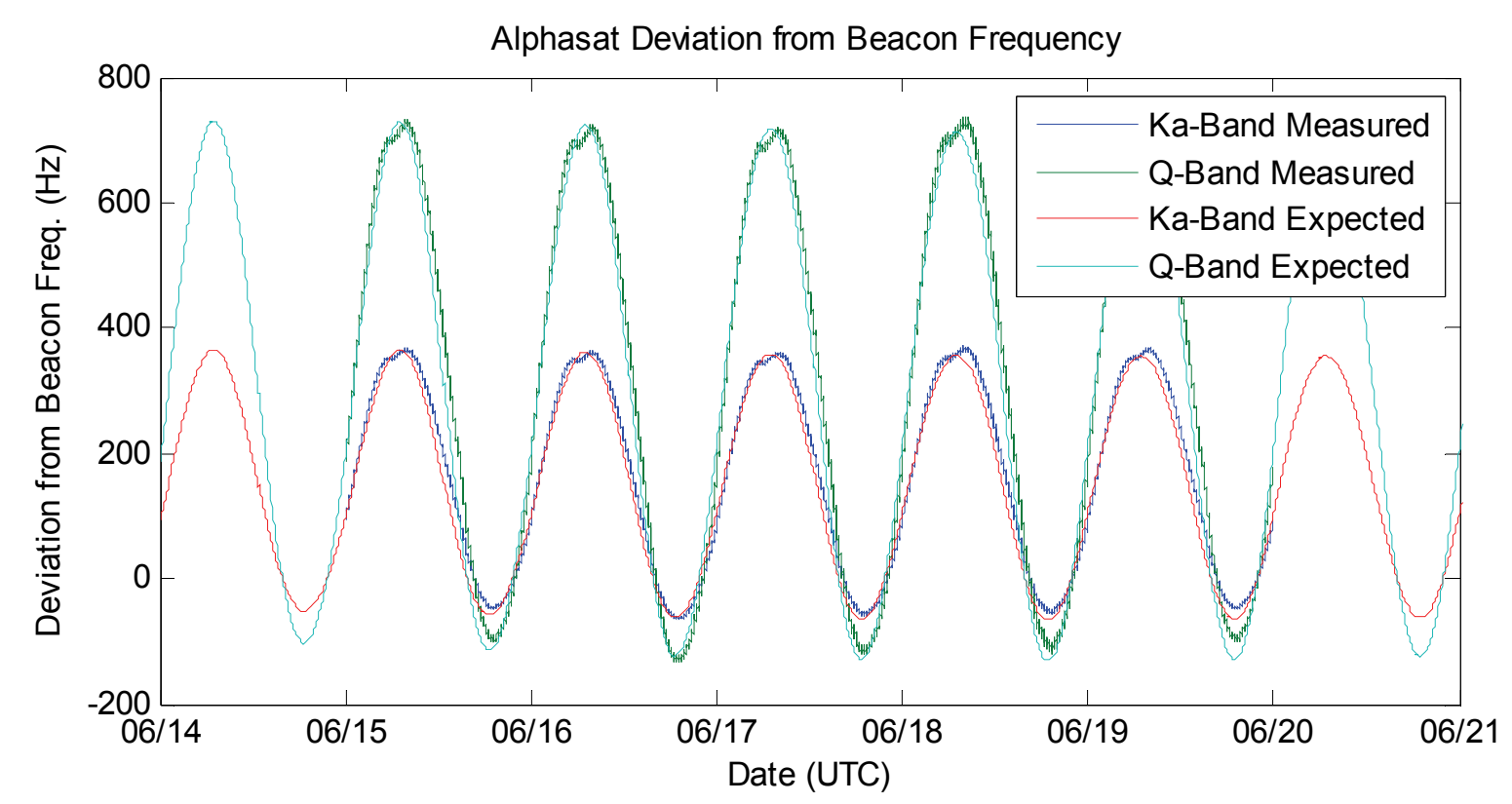

When compared to the expected doppler shift (derived from satellite position data), the beacon offset and drift can be estimated.

\begin{tabular}{|l|c|c|}
\hline & Drift & Offset \\
\hline Ka-Band Beacon & $15.7 \mathrm{~Hz} /$ day & $150 \mathrm{~Hz}$ \\
\hline Q-Band Beacon & $31.6 \mathrm{~Hz} /$ day & $300 \mathrm{~Hz}$ \\
\hline
\end{tabular}




\section{Conclusions}

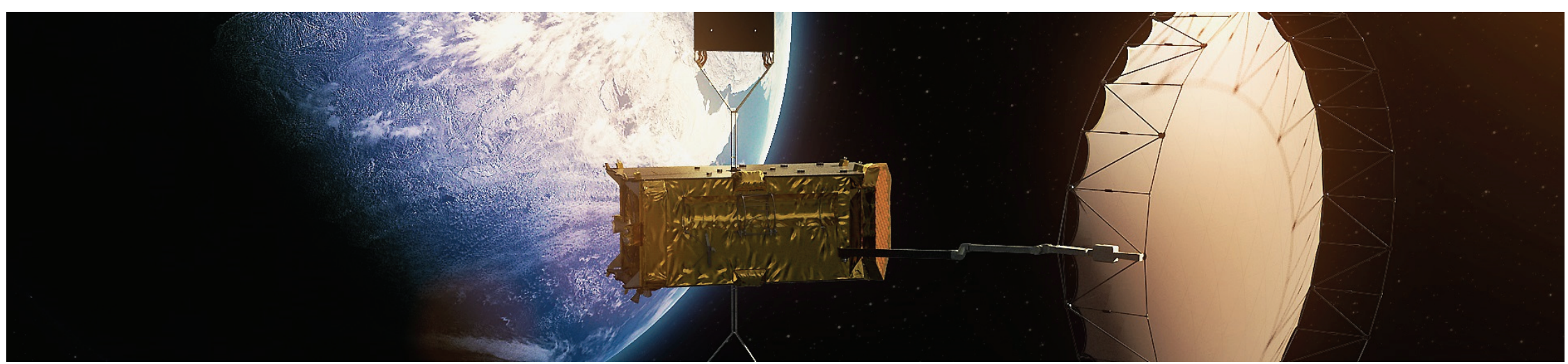

\section{Conclusions:}

Both in simulation and in measurement, the estimator-based receiver proved more accurate than the purely FFT-based approach for both frequency and power measurements.

Most of the selected algorithms performed comparably; each estimator was shown to calculate the frequency to within $\pm 1 \mathrm{~Hz}$ given an SNR above $-24 \mathrm{~dB}$, although the Buneman algorithm was eliminated for this application given its reduced performance near bin frequencies.

If operation at lower SNR is required, the inclusion of a priori information on where to search for the peak can be implemented to improve performance. This was implemented in the Alphasat receiver design, but only utilized during low-SNR conditions. 


\section{Future Work}

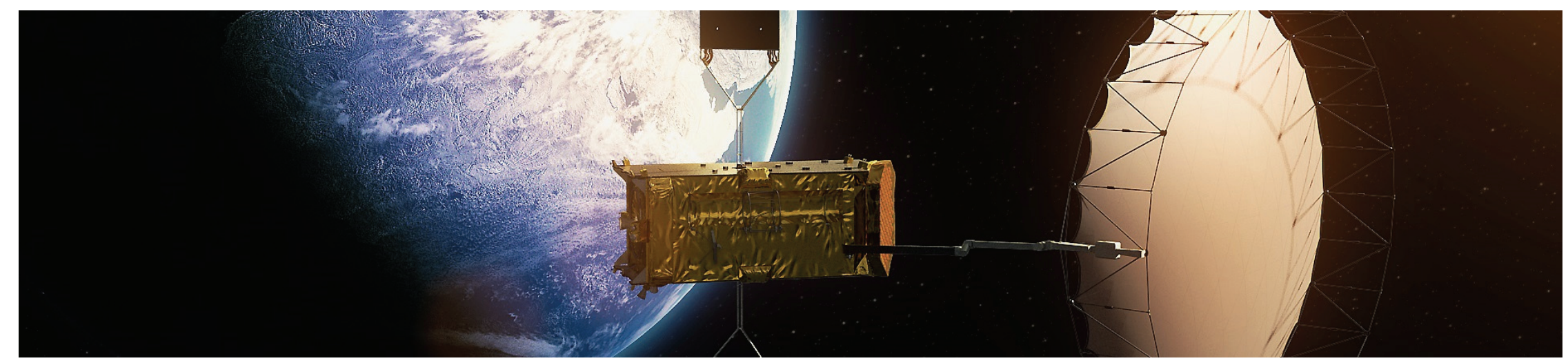

\section{Future Work:}

Near-Term:

- Continued Data Collection

- $\geq 5$ years

- Statistical Characterization of Milan at $20 \mathrm{GHz} \& 40 \mathrm{GHz}$

\section{Long-Term:}

- Further Optimization of Receiver Algorithm for Future Iterations

- Additional Frequency Bands (V/W/Optical)

- Additional Sites 


\section{Contact Information}

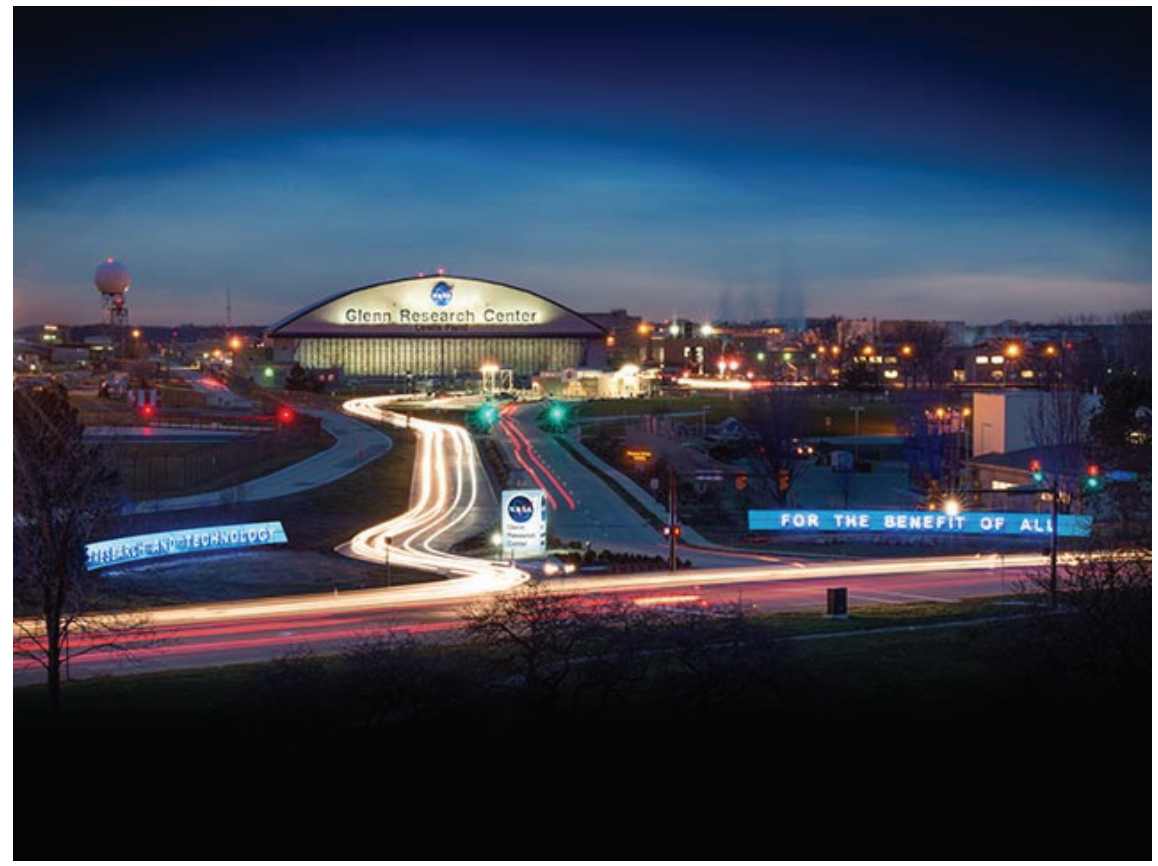

NASA Glenn Research Center 21000 Brookpark Rd. MS 54-1 Cleveland, Ohio 44135, USA

\section{James Nessel}

Principal Investigator, RF Propagation Task 216.433.2546 james.a.nessel@nasa.gov

\section{Michael Zemba}

Research Engineer

216.433.5357

michael.j.zemba@nasa.gov

\section{Jacquelynne Morse}

Research Engineer

216.433.5468

jacquelynne.r.morse@nasa.gov

\section{Félix Miranda}

Chief, Advanced High Frequency Branch

216.433.6589

felix.a.miranda@nasa.gov 


\section{References}

[1] A.R. Thompson, J.M. Moran, and G.W. Swenson, Interferometry and Synthesis in Radio Astronomy, Second Edition, John Wiley \& Sons, 2001.

[2] Quinn, B.G. and Fernandes, J.M., "A fast technique for the estimation of frequency", Biometrika, 78(3) (1991), pp. 489-497.

[3] National Instruments. Buneman Frequency Estimator VI [Online] Available:

http://digital.ni.com/public.nsf/allkb/4D01B90 DCBAD81C0862570FC005A914E.

[4] Quinn, B.G., "Estimating frequency by interpolation using Fourier coefficients," IEEE Trans. Sig. Proc. Vol 42 No 5, May 1994, pp12641268.

[5] Jacobsen, E.A. "On Local Interpolation of DFT Outputs," Available:

http://www.ericjacobsen.org/FTinterp.pdf, Fall, 1994.

[6] Macleod, M.D., "Fast Nearly ML Estimation of the Parameters of Real or Complex Single Tones or Resolved Multiple Tones," IEEE Trans. Sig. Proc. Vol 46 No 1, January 1998, pp141-148.
[7] R. J. Acosta, B. D. Frantz, J. A. Nessel, and D. D. Morabito, "Goldstone Site Test Interferometer," in 13th Ka and Broadband Communications Conference, Turin, Italy, 2007.

[8] R. J. Acosta, J. A. Nessel, and D. D. Morabito, "Data Processing for Atmospheric Phase Interferometers," in 14th Ka and Broadband Communications Conference, Matera, Italy, 2008. 